\title{
PENYULUHAN IMUNISASI DI DESA PANGKALAN BARU KECAMATAN SIAK HULU KAB. KAMPAR TAHUN 2018
}

\author{
Nelly Karlinah ${ }^{1)}$ Nur Israwati $^{2)}$ Melti Marzellina ${ }^{3)}$ \\ STIKes Hang Tuah Pekanbaru \\ email: nellykarlinah87@gmail.com
}

\begin{abstract}
The success of health development is strongly influenced by the availability of healthy, skilled and skilled human resources, and is compiled in one health program with an integrated planning supported by falid epidemiological data and information. Immunization is one of the efforts to create a quality generation of the nation. Immunization needs to be continuously improved to achieve a high level of population immunity so that it can break the PD3I chain of transmission. With advances in science and technology, immunization efforts can be more effective and efficient with the hope of making a real contribution to the welfare of children, mothers and other communities. The results of the service obtained in the Pangkalan Baru village, upstream Siak sub-district, the UCI (Utilization Child Immunization) has not been achieved where the achievement of immunization is $95 \%$, for that it is necessary to increase knowledge through immunization education. This immunization counseling was held on October 10-12 2018. The results of this counseling obtained increased knowledge of mothers about knowledge about immunization in Pangkalan Baru Village, Kec. Siak Hulu Kab. Kampar of the Year 2018.
\end{abstract}

Keywords: Immunization, Extension, Desa Pangkalan Baru Kec. Siak Hulu

\begin{abstract}
ABSTRAK
Keberhasilan pembangunan kesehatan sangat di pengaruhi oleh tersedianya sumber daya manusia yang sehat, terampil dan ahli, serta disusun dalam satu program kesehatan dengan perencanaan terpadu yang didukung oleh data dan informasi epidemiologi yang falid. Imunisasi termasuk salah satu upaya untuk menciptakan generasi bangsa yang berkualitas. imunisasi perlu terus ditingkatkan untuk mencapai tingkat population imunity (kekebalan masyarakat) yang tinggi sehingga dapat memutuskan rantai penularan PD3I. Dengan kemajuan ilmu pengetahuan dan teknologi, upaya imunisasi dapat semakin efektif dan efisien dengan harapan dapat memberikan sumbangan yang nyata bagi kesejahteraan anak, ibu serta masyarakat lainnya. Hasil pengabdian didapatkan di desa pangkalan baru kecamatan siak hulu masih belum tercapainya UCI (Utilization Child Imunization) dimana penetapan capaian imunisasi $95 \%$, untuk itu perlu adanya peningkatan pengetahuan melalui penyuluhan imunisasi. Penyuluhan imunisasi ini dilaksanakan pada tanggal 10-12 Oktober 2018. Hasil dari penyuluhan ini di dapatkan meningkatnya pengetahuan ibu terhadap pengetahuan tentang imunisasi di Desa Pangkalan Baru, Kec. Siak Hulu Kab. Kampar Tahun 2018.
\end{abstract}

Kata Kunci : Imunisasi, Penyuluhan, Desa Pangkalan Baru Kec. Siak Hulu. 


\section{PENDAHULUAN}

Kesehatan sebagai salah satu unsur kesejahteraan umum perlu diwujudkan sesuai dengan cita-cita bangsa Indonesia sebagaimana di maksud dalam UUD 1945 melalui pembangunan nasional yang berkisinambungan berdasarkan Pancasila dan UUD 1945. Keberhasilan pembangunan kesehatan sangat di pengaruhi oleh tersedianya sumber daya manusia yang sehat, terampil dan ahli, serta disusun dalam satu program kesehatan dengan perencanaan terpadu yang didukung oleh data dan informasi epidemiologi yang falid. Pembangunan bidang kesehatan di indonesia saat ini mempunyai beban ganda.

Penyakit menular masih merupakan masalah, sementara penyakit degeneratif juga muncul sebagai masalah. Penyakit menular tidak kenal batas wilayah administrasi, sehingga menyulitkan pemberantasannya. Dengan tersedianya vaksin yang dapat mencegah penyakit menular pertama, maka tindakan pencegahan untuk mencegah berpindahnya penyakit dari satu daerah atau Negara ke Negara lain dapat dilakukan dalam waktu relatif singkat dan dengan hasil yang efektif.

Dengan upaya imunisasi terbukti bahwa penyakit cacar telah terbasmi dan indonesia dinyatakan bebas dari penyakit cacar sejak tahun 1974. Mulai tahun
1977, upaya imunisasi diperluas menjadi program pengembangunan imunisasi dalam rangka pencegahan penularan terhadap penyakit yang dapat mencegah dengan imunisasi (PD3I) yaitu, Tuberculosis, Ifteri, Pertusis, Campak, Polio, Tetanus serta Hepatitis B. Walaupun PD3I sudah dapat ditekan, cakupan imunisasi harus dipertahankan tinggi dan merata. Kegagalan untuk menjaga tingkat perlindungan yang tinggi dan merata dapat menimbulkan letusan (KLB) PD3I. Untuk itu,m upaya imunisasi perlu disertai dengan upaya surveilans epidemioligi agar setiap peningkatan kasus penyakit atau terjadinya klb dapat terdeteksi dan segera diatasi.

Dalam PP no 25 tahun 2000 kewenangan surveilans epidemiologi, termasuk penanggulangan klb merupakan kewenangan bersama antara pemerintah pusat dan pemerintah Provinsi. Selama beberapa tahun terakhir ini, kekhwatiran akan kembalinya beberapa penyakit menular dan timbulnya penyakit-penyakit menular lainnya kian meningkat. Kemajuan ilmu pengetahuan dan teknologi membawa program imunisasi kedalam penyelenggaraan yang bermutu dan efisien. Upaya tersebut didukung dengan kemajuan yang pesat dalam bidang penemuan vaksin baru (rotavirus, javanese encphapalitis, dan lain-lain). 
Beberapa jenis vaksin dapat digabung sebagai vaksin kombinasi yang terbukti dapat meningkatkan cakupan imunisasi, mengurangi jumlah suntikan dan kontak dengan petugas im unisasi. Dari uraian diatas jelaslah bahwa upaya imunisasi perlu terus ditingkatkan untuk mencapai tingkat population imunity (kekebalan masyarakat) yang tinggi sehingga dapat memutuskan rantai penularan PD3I. Dengan kemajuan ilmu pengetahuan dan teknologi, upaya imunisasi dapat semakin efektif dan efisien dengan harapan dapat memberikan sumbangan yang nyata bagi kesejahteraan anak, ibu serta masyarakat lainnya.

\section{METODE PENERAPAN}

Memberikan informasi bagi ibu-ibu khususnya ibu-ibu yang memiliki bayi dan balita di Desa Pangkalan Baru kec. Siak Hulu Kab. Kampar tentang Imunisasi.

Setelah mengikuti penyuluhan responden diharapkan :

1. Dapat memberikan informasi mnegenai manfaat imunisasi pada bayi dan balita.

2. Dapat membawa bayi dan balitanya ke tenaga kesehatan terdekat untuk diberikan imunisasi sesuai dengan usianya

\section{HASIL DAN PEMBAHASAN}

\section{A. Hasil Pelaksanaan}

Kegiatan pengabdian yang dilaksanakan pada ibu yang mempunyai bayi dan balita di Desa Pangkalan Baru Kec. Siak Hulu Kab. Kampar telah berlangsung dengan baik. Hal ini terlihat dari animo masyarakat khusunya ibu yang mempunyai bayi dan balita. Kegiatan penyuluhan ini berjalan dengan baik ditunjukkan dengan animo masyarakat sangat tinggi untuk meningkatkan pengetahuan tentang imunisasi. Ketua kader dan bidan desa sangat antusias untuk mengajak warganya untuk ikut kegiatan penyuluhan imunisasi ini, apalagi imunisasi ini merupakan salah satu program pemerintah dalam membentuk generasi anak bangsa yang berkualitas. Semoga kegiatan ini dapat membawa manfaat dan berlangsung secara kontinu, hasil dari kegiatan penyuluhan ini masyarakat sudah mengerti tentang pentingnya imunisasi dan akan segera membawa anak-anaknya untuk segera di imunisasi 


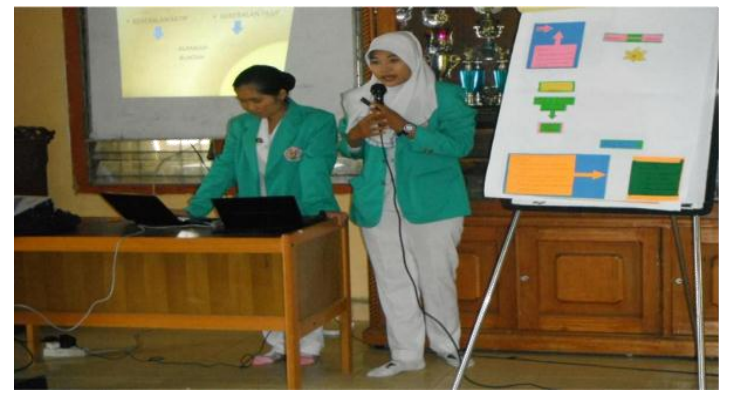

Gambar 1. Penyampaian materi

Penyuluhan Imunisasi

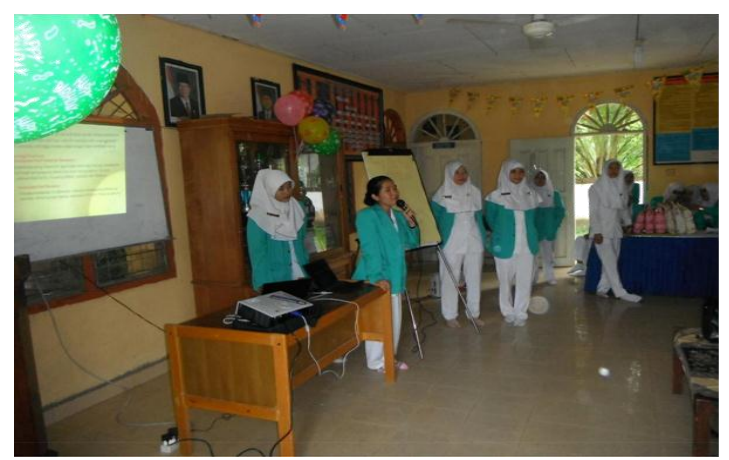

\section{B. Pembahasan}

Kegiatan

penyuluhan

Memberikan informasi bagi ibu-ibu khususnya ibu-ibu yang memiliki bayi dan balita di Desa Pangkalan Baru kec. Siak Hulu Kab. Kampar tentang Imunisasi) telah dilaksanakan pada "10-13 Oktober 2018 " Berdasarkan pengamatan selama kegiatan berlangsung, kegiatan pegabdian pada masyarakat ini memberikan hasil sebagai berikut: Setelah mengikuti penyuluhan responden dapat memberikan informasi mnegenai manfaat imunisasi pada bayi dan balita dan dapat membawa bayi dan balitanya ke tenaga kesehatan terdekat untuk diberikan imunisasi sesuai dengan usianya

\section{KESIMPULAN}

Setelah mengikuti penyuluhan responden dapat memberikan informasi mnegenai manfaat imunisasi pada bayi dan balita dan dapat membawa bayi dan balitanya ke tenaga kesehatan terdekat untuk diberikan imunisasi sesuai dengan usianya

\section{DAFTAR PUSTAKA}

Albertina, M., Febriana, S., Firmanda, W., Permata, Y., \& Gunardi, H. 2009. Kelengkapan Imunisasi Dasar Anak Balita dan FaktorFaktor yang Berhubungan di Poliklinik Anak Beberapa Rumah Sakit di Jakarta dan Sekitarnya pada Bulan Maret 2008. Sari Pediatri, Vol. 11, No. 1, Juni.

Ali, M. 2003. Pengetahuan, Sikap dan Perilaku Ibu Bekerja dan Ibu Tidak Bekerja Tentang Imunisasi. Tesis FK USU.

Depkes RI. 2009. Buku Kesehatan Ibu dan Anak. Jakarta.

Hadinegoro, S.R., Pusponegoro, H.D., Soedjatmiko, \& Oswari, H. 2011. Panduan Imunisasi Anak : mencegah lebih baik daripada mengobati. Jakarta : Satgas Imunisasi IDAI. 
Marmi \& Rahardjo, K. 2012. Asuhan Neonatus, Bayi, Balita, dan Anak

Pra Sekolah. Yogyakarta : Pustaka Belajar

Palupi, A.W. 2011. Pengaruh Penyuluhan Imunisasi Terhadap Peningkatan Pengetahuan dan Sikap Ibu Tentang Imunisasi Dasar Lengkap Pada Bayi Sebelum Usia 1 Tahun. Tesis Megister Kedokteran Keluarga FK UNS.
Ranuh, I.G.N., Suyitno, H., Hadinegoro, S.R., Kartasasmita, C.B., Ismoedijanto, Soedjatmiko. 2011. Pedoman Imunisasi di Indonesia. Jakarta : Satgas Imunisasi IDAI

Sarwono, S.W., Meinarno, E.A., Takwin, B. 2011. Psikologi Sosial. Jakarta : Salemba Humanika.

WHO. 2013. Global Immunization Data. www.who.int. 